\title{
STRUKTURERING AS TEGNIEK VAN MOTIEF-AANDUIDING IN AISKHULOS SE PERSE
}

\section{Francois Saayman (Universiteit van die Noorde)}

In navorsing oor motiewe en temas in letterkundige werk is dit van groot waarde as die teks dit self deur een of ander tegniek aandui. Sodoende kan subjektiewe raaiwerk grootliks uitgeskakel word. In die Oresteia, byvoorbeeld, maak Aiskhulos op só 'n manier van dubbelsinnigheid gebruik dat ' $n$ woord se metaforiese betekenis in die onmiddellike konteks inpas, maar die letterlike betekenis 'n motief skep wat meewerk aan 'n tema. In Ag. 143 sê die teks dat Artemis "aangenaam teenoor die

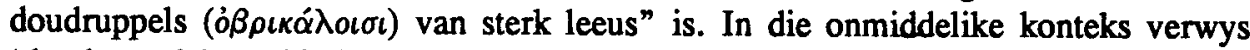
'doudruppels' na 'kinders', maar die letterlike betekenis vorm deel van 'n tema van bloed wat vergiet word, en kulmineer in Agamemnon se bloed wat Klutaimnestra soos 'n 'reënbui' ( $\psi \alpha \alpha \alpha ́ \delta$ ) tref (Ag. 1390) (Saayman 1994:3). Maar in die Perse word so 'n sterk verskil tussen metaforiese en letterlike betekenis skynbaar nie dikwels gebruik nie. Wanneer dubbelsinnighede wel gebruik word, is dit baie meer 'gewoon', soos toúplos eers as 'ywerig' (73 en 137) en dan as 'oorywerig' (718 en

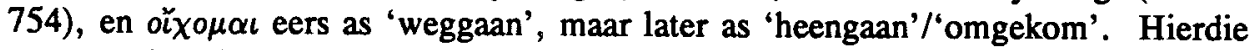
gewone tipe dubbelsinnigheid word egter nie baie gebruik nie. Die tegniek wat hoofsaaklik in die Perse gebruik word, is om woorde deur middel van stilistiese strukturering uit te lig. Woorde kan semanties of met mekaar kontrasteer word, soos $\pi \rho \varepsilon \sigma \beta \varepsilon i \alpha \nu$ ('ouderdom', r.4) en $\nu \varepsilon \dot{o} \nu$ ('jonk', r.13), of identifiseer word, soos $\dot{\varepsilon} \delta \rho \alpha \nu^{\prime} \omega \nu$ ('paleis', r.4) en $\beta \alpha \sigma i \lambda \varepsilon i \varphi$ ('koninklik', r.8). Beide tipes word deur strukturele tegnieke aangedui. In hierdie artikel word gewys op die unieke strukturering van Perse 1-15, wat duidelik ten doel het om motiewe aan te dui.

Die eerste vyftien reëls van die Perse vertoon 'n besondere struktuur deurdat $r$. 12-15 in 'n neutedop beide die stylfigure van die voorafgaande rr. 1-11 herhaal en die semantiese essensie daarvan opsom. In $\mathrm{rr}$. 1-11 van die tradisionele binnekomslied identifiseer die koor hulself as dramatiese karakters en begin terselfdertyd die agtergrond skets van die gebeure wat gaan plaasvind. Die identifikasie en agtergrond alterneer egter heeltyd, sodat dit struktureel van mekaar geskei word, waardeur die grondslag vir fynere strukturering geskep word.

In die volgende strukturele voorstelling van die teks word rr. 1-11 as deel A aangedui, en die herhalende rr. 12-15 as deel B. In A is alle verwysings na die koor na links geskuif en alfabeties genommer, terwyl alle verwysings na die Persiese leër en hul aanvoerder Xerxes effens na regs geskuif en numeries genommer is. Die ortografies aangeduide woorde is woorde wat deur die strukturering gemerk word en dus van besondere belang is. 


\section{Struktuurontleding}

A

(a) $\mathrm{T} \alpha ́ \delta \varepsilon$

(1) $\mu \grave{\nu} \nu$

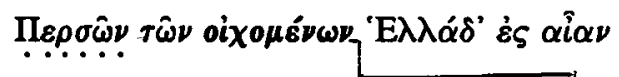

(b) $\pi \iota \sigma \tau \grave{\alpha} \kappa \alpha \lambda \varepsilon \hat{\imath} \tau \alpha \iota$,

(2) $\quad \kappa \alpha i \quad \tau \hat{\omega} \nu \dot{\alpha} \phi \nu \varepsilon \hat{\omega} \nu \kappa \alpha i \quad \underline{\pi 0 \lambda v x \rho u ́ \sigma \omega \nu} \quad \dot{\varepsilon} \delta \rho \dot{\alpha} \nu \omega \nu$

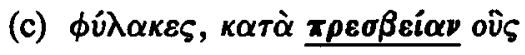

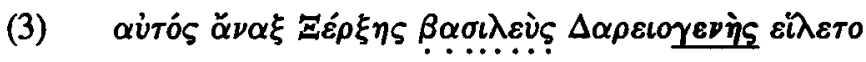

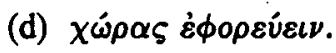

(4) $\quad \dot{\alpha} \mu \phi \grave{i} \delta \grave{\varepsilon}$

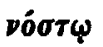
$\tau \hat{\varphi} \beta \alpha \sigma \lambda \lambda \varepsilon i \varphi$

(5) $\quad \alpha i$

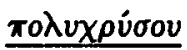

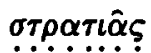

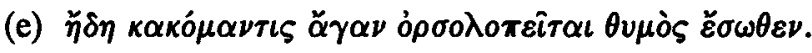

\section{B}

(1) $\underline{\pi \hat{\alpha} \sigma \alpha} \gamma \grave{\alpha} \rho$ i $\sigma \chi \grave{v} \varsigma$

$$
\downarrow \underline{\nu \varepsilon \dot{o \nu}} \delta^{\prime} \check{\alpha} \nu \delta \rho \alpha \beta \alpha \tilde{u} \zeta \varepsilon l,
$$

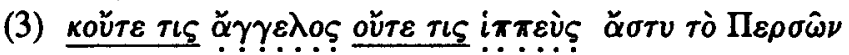

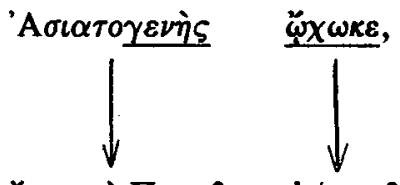

Vertaling:

Ons word die 'Betroubares' genoem van die Perse wat weggegaan het na die land van Hellas, en ons is die bewakers van die skatgevulde paleis. Op grond van ons ouderdom het ons heer, koning Xerxes, seun van Darius, ons aangestel om oor die land te waak. Ons is bekommerd oor die terugkeer van die koning en die skatbelaaide leër. Want die hele mag gebore uit Asië is weg, morrend ${ }^{1}$ dat die man te jonk is; en nóg enige boodskapper, nog enige ruiter keer terug na die stad van die Perse.

1 Die subjek van $\beta \alpha \dot{u} \zeta \measuredangle \iota$ skep 'n probleem wat verder aan behandel sal word. 
In deel $\mathbf{A}$ is daar twee stelle woorde wat lyk asof dit retoriese figure moet wees, naamlik:

$\begin{array}{lll}\Pi \varepsilon \rho \sigma \hat{\omega} \nu & \text { oix } \alpha \mu \varepsilon \dot{\varepsilon} \omega \nu & \mathrm{A}(1) \\ \pi \circ \lambda \nu \chi \rho \dot{v} \sigma \omega \nu & \dot{\varepsilon} \delta \alpha \dot{\nu} \nu \omega \nu & \mathrm{A}(2)\end{array}$

en

\begin{tabular}{|c|c|}
\hline 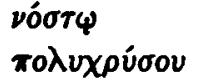 & $\begin{array}{l}\tau \hat{\varphi} \beta \alpha \sigma l \lambda \varepsilon i \varphi \\
\sigma \tau \rho \alpha \tau i \hat{\alpha} \varsigma\end{array}$ \\
\hline
\end{tabular}

Daar is egter nie werklik chiasme of paralellisme in die individuele stelle nie, maar die simmetriese plasing in die stuk is alreeds ' $n$ aanduiding van ringkomposisie. Dit

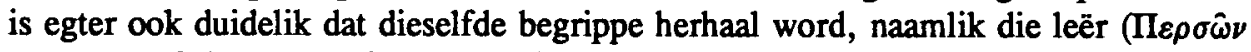
en $\sigma \tau \rho \alpha \tau \iota \hat{\alpha} \varsigma)$, verwysings na die koning ( $\dot{\varepsilon} \delta \rho \alpha \nu \hat{\omega} \nu$ en $\beta \alpha \sigma \iota \lambda \varepsilon \dot{\varphi})$, rykdom

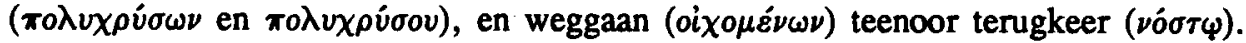

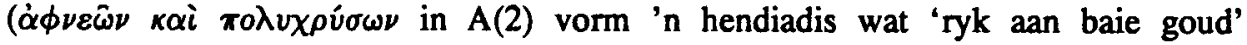
beteken, maar net $\pi 0 \lambda v x \rho \dot{v} \sigma \omega \nu$ word herhaal en is dus van stukturele betekenis.)

Inderdaad vind retoriese strukturering plaas tussen elemente van die twee stelle, waarvan die belangrikste ' $n$ chiasme is wat aansluit by die middel van A om 'n ringkomposisie te skep:

$\left[\begin{array}{cc}\Pi \varepsilon \rho \sigma \hat{\omega} \nu & \mathrm{A}(1) \\ -\dot{\varepsilon} \delta \rho \dot{\alpha} \nu \omega \nu & \mathrm{A}(2) \\ \beta \alpha \sigma \iota \lambda \varepsilon \dot{v} \varsigma & \mathrm{A}(3) \\ \beta \alpha \sigma \iota \lambda \varepsilon i \varphi & \mathrm{A}(4) \\ \sigma \tau \rho \alpha \tau i \hat{\alpha} \varsigma & \mathrm{A}(5)\end{array}\right.$

Voorlopig is dit die veiligste om net te sê dat 'n onderskeid gemaak word tussen die leër aan die buitekant en die koning, Xerxes, aan die binnekant. Hierdie onderskeid ontwikkel in die drama tot ' $n$ teenstelling tussen die twee partye, naamlik dat Xerxes verantwoordelik is vir die dood van 'n geweldige hoeveelheid soldate. Deel B vertoon alreeds hierdie kontras en stel dit as 'n konflik tussen die twee partye voor.

Alhoewel die buitenste dele van B 'n drievoudige paralellisme vorm, met 'die hele mag' teenoor 'geen boodskapper of ruiter', 'Asië' coreenstemmend met 'Persië'; en 'weggaan' teenoor 'terugkeer', omraam die paralellisme 'n middelpunt $(\mathrm{B}(2))$. Aan die buitekant is die leër wat weg is van hul land, met Xerxes ( $\nu \varepsilon \dot{\nu}$ $\check{\alpha} \nu \delta \rho \alpha)$ in die middel. In die middel word gemor ( $\beta \alpha \tilde{u} \zeta \varepsilon \iota)$ oor die jong koning.

Holtsmark (1970:13) wys op 'n ringkomposisionele verband tussen deel B en rr. 59-60. In die lig van struktuur B, is dit egter beter om reëls 56-60 as 'n eenheid te neem, omdat dit dieselfde struktuur as deel $B$ vertoon en daardeur die 
ringkomposisionele aansluiting by B versterk. Ons kan hierdie ringkomposisie BB noem:

\section{BB}

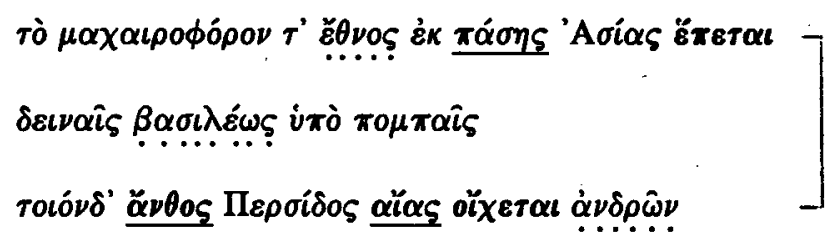

Net soos in deel B, is Asië in die eerste lid en Persië in die laaste lid. Die leër wat weg is, is in die buitenste lede, en Xerxes is weereens in middel. Verder sluit $\bar{\varphi} \chi \omega \kappa \varepsilon$ van B (1) ringkomposisioneel aan by ő̌x $\tau \tau \alpha \iota$ aan die einde van BB. So ook sluit

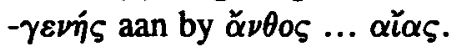

Alhoewel $B$ en BB ' $n$ ring vorm, sluit $B$ ook by $A$ aan as 'n abstraksie van A. Hierdie artikel konsentreer op die analise van $A$ en $B$, maar weens die ringkomposisionele verbinding is dit logies dat BB sekere onduidelik punte punte in $A$ en $B$ sal verklaar.

Groeneboom (1960:75-78) gee 'n lang bespreking van wat die subjek van $\beta \alpha \tilde{u} \zeta \varepsilon \iota$, in die middel van B, moet wees. Dat die leër die subjek kan wees, word as onwaarskynlik beskou omdat die koor nie kan weet wat die leër sê nie. Hy aanvaar

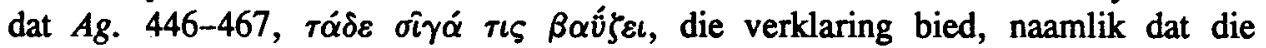
agtergeblewenes mor (1960:76-77). Neem ons egter die ringkomposisie van B en

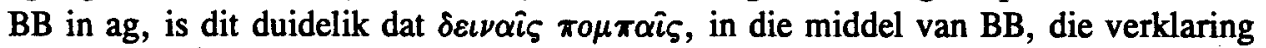
bied vir $\beta \alpha \hat{v} \zeta \varepsilon$. Die leër is gemobiliseer deur 'n outokraat wat dreigemente, nie oorreding, gebruik het. In hierdie konteks het die leër gemor, en gevolglik moet $\beta \alpha \hat{v}\} \varepsilon l$, vanuit ringkomposisionele perspektief, as 'n historiese praesens gesien word. So verdwyn die probleem dat die koor nie kon weet wat die leër sê nie. Hierdie idee word later weer opgeneem (584-597) as oor die bevryding van die

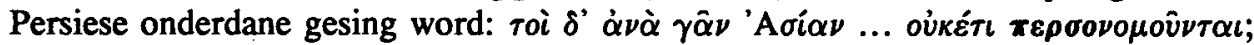

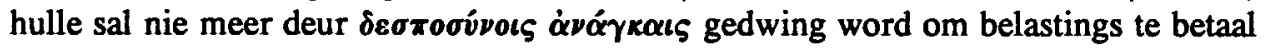

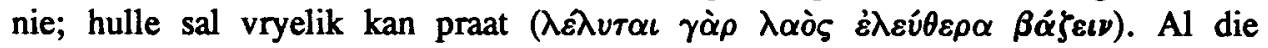
vetgedrukte begrippe hier kom ook in $B$ en $B B$ voor.

Beide dele A en B vertoon ringkomposisie, met die leër aan die buitekant en Xerxes in die middel. Maar waar deel A net stilisties 'n onderskeid tussen die leër en die koning suggereer, is deel B meer eksplisiet ten opsigte van die volgende twee punte:

- Geen soldate keer terug nie.

- Die leër mor oor die koning.

Hiermee word die temas van lewensverlies en Xerxes as oorsaak daarvan, ingelei.

In die twee woordstelle in A is ook die volgende parallelisme, wat die simmetrie rondom die middelpunt versterk: 


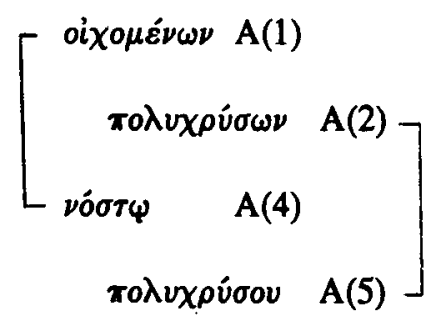

Twee aspekte word hier beklemtoon, naamlik die wegwees en rykdom. Beide verskil egter van deel B. In deel A is die weggaan gekoppel aan die leêr, maar die terugkeer eers aan die koning en daarna aan die leër ( deel $B$ word beide die weggaan en terugkeer net aan die leër gekoppel in die buitekant van die ringkomposisie. Aan die ander kant word rykdom in A deur die stylfiguur beklemtoon, maar $B$ bevat geen verwysing na rykdom nie.

Dit is reeds duidelik dat $B$ ' $n$ abstraksie van $A$ is, en daarom is dit belangrik om vas te stel hoekom rykdom nie in B voorkom nie, as dit in A dan so belangrik is. Die antwoord lê in kontras. Rykdom word beskryf as $\pi 0 \lambda v x \rho v \sigma \omega \nu / o v-$ daarteenoor

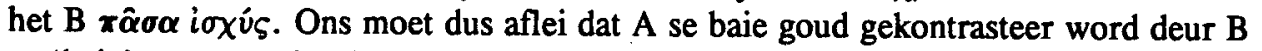
se 'baie' manne. Dit wil sê goud maak plek vir soldate. In A sluit die koor se vrese (A(e)) by implikasie verlies aan rykdom in, maar in B is dit nie meer ter sake nie. Die laaste retoriese verbindings tussen die twee woordstelle in $A$ is:

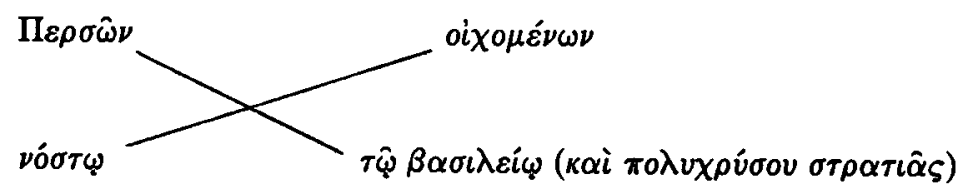

Alhoewel vó $\tau \tau \varphi$ sintakties saamgaan met $\beta \alpha \sigma i \lambda \varepsilon i \varphi$ en $\sigma \tau \rho \alpha \tau i \hat{\alpha} \varsigma$, is dit waarskynlik dat, omdat $\beta \alpha \sigma i \lambda \varepsilon i \varphi$ eerste genoem word, asook die feit dat in die ander gevalle die strukture tussen individuele woorde lê, hierdie chiasme wel struktureel net $\beta \alpha \sigma \iota \lambda \varepsilon i \varphi$ betrek, wat dan twee kontraste gee: 'gaan' teenoor 'terugkeer', en 'Perse' teenoor 'die koning'. Laasgenoemde kontras sal goed inpas by die kontras tussen die twee partye wat reeds deur die ander strukture bewerkstellig is. Sodoende is dit moontlik prolepties van latere verwikkelinge, naamlik dat Xerxes alleen terugkeer, terwyl sy leërs omgekom het. Van moontlike belang is Holtsmark (1970:21) se waarneming

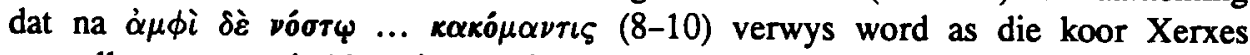

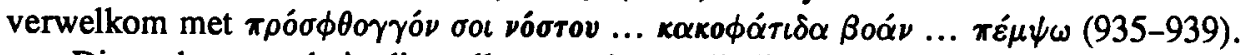

Die ander woorde in die stelle vorm 'n parallellisme:
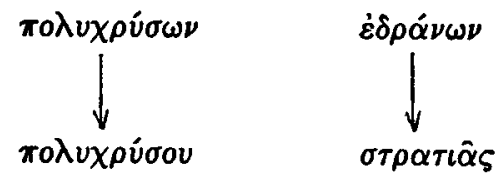

Eers word rykdom aan die paleis, dit wil sê die koning gekoppel, en dan aan die leër. Groeneboom (1960:9) noem dat onder andere Herodotos en Plutarchos melding 
maak van die groot skatte wat die Persiese leërs gewoonlik in hulle kampe gehad het. Hier is weer 'n onderskeid tussen die koning en die leër.

Ter opsomming: Al die verbindings tussen die twee simmetries geplaasde woordstelle in A vind oor die middelpunt heen plaas en versterk die ringkomposisionele aard van deel A. Die belangrikste van hierdie strukture is die simmetriese patroon van $\Pi \varepsilon \rho \sigma \hat{\omega} \nu . . . \dot{\varepsilon} \delta \rho \alpha \dot{\nu} \hat{\omega} \nu-\beta \alpha \sigma \iota \lambda \varepsilon \dot{\varphi} \varphi . . \sigma \tau \rho \alpha \tau \iota \hat{\alpha} \varsigma$ wat twee ringe vorm om $\beta \alpha \sigma \lambda \lambda \varepsilon v$ s in die middel van die stuk. Hierdeur word die koning teenoor die leër gestel, soos baie duideliker herhaal word in die bondige deel B, waar die koning weens sy jeug gekritiseer word.

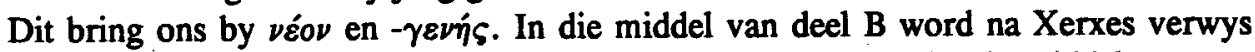

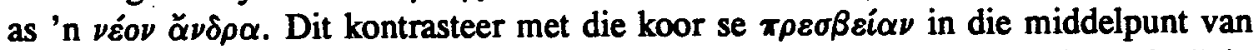
A. Die tema van jeugdigheid sluit ook aan by $(\Delta \alpha \rho \varepsilon \iota 0) \gamma \varepsilon \nu \eta \dot{s}$ ('gebore uit Darius') in

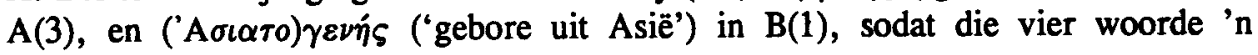
chiasme vorm:

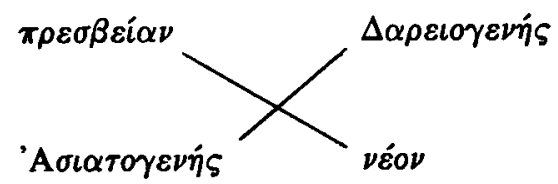

Ook hierdie chiasme bevat weer 'n kontras tussen die koning en die leër naamlik

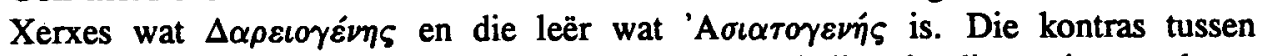
Xerxes en die leër is inligting wat reeds deur herhaling in die vorige strukture vasgelê is. Dit word nou weer aangeroer ten einde 'n nuwe element by te bring, naamlik die jeug van Xerxes teenoor die ouderdom van die koor. Die chiastiese

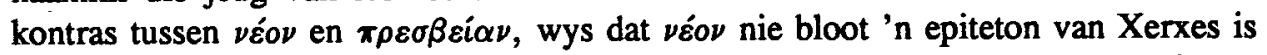
nie, maar van wesenlike belang vir die drama is. Hier pas 'n aspek van Groeneboom (1960:77) se interpretasie van B(2), naamlik (iemand) "mompelt in stilte ... "(te) jong is de man'". Die elemente in hierdie chiasme ontwikkel later in twee hoof temas naamlik:

1) Xerxes maak oordeelsfoute weens sy jeug, wat in skerp teenstelling staan met

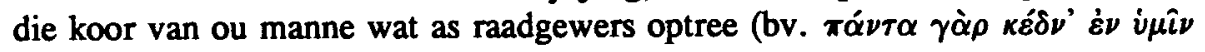

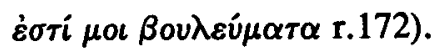

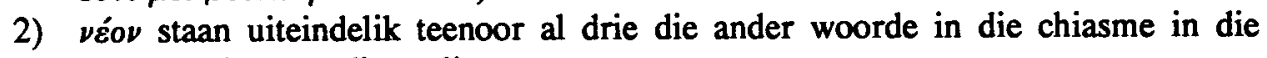
ontwikkeling van die verlies-tema.

(a) Eerstens is Xerxes ' $n$ kind wat die ander kinders van die land

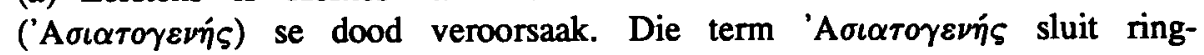
komposisioneel aan by BB se $\alpha \nu \theta 0 \varsigma$ П waarin die soldate blomme van die land genoem word; maar dis meer as net ' $n$ standaard metafoor, omdat herhaaldelik na die aarde ( $\gamma \hat{\alpha}$ en $\chi \theta \dot{\omega} \nu$ ) verwys word wat beroof is van haar kinders $(512,548,922,925)$.

(b) Net soos die aarde van sy land, word die ouers, vrouens en kinders van die soldate beroof (vaagweg kollektief aangedui deur $\pi \rho \varepsilon \sigma \beta \varepsilon i \alpha \nu$ ).

(c) Laastens kom $\pi \rho \varepsilon \sigma \beta \varepsilon i \alpha \nu$ en $\Delta \alpha \rho \varepsilon i o-$ ter sprake as Darius in 'n aangrypende stuk (759-786) met bitterheid 'n oorsig gee oor Xerxes se voorgeslagte in die 
dinastie, en Xerxes verwyt dat hy meer skade aan sy erfenis aangebring het as enige van hierdie 'ouers', selfs meer as Mardos, wat vermoor moes word om sy swak regering te beeindig. Die kind van die land, wat die ander kinders se dood veroorsaak het, word effektief deur sy eie vader ter dood veroordeel. In totaal kry hierdie skrywer die indruk dat daar ' $n$ allesomgewende suggestie is van 'n kind-ouer konflik, as 'n abstrakte idee spruitend uit die skade wat Xerxes sy land, die ouers van die soldate, en sy dinastie aandoen. Hierdie konflik vervang die militêre konflik tussen Persië en Griekeland, wat op die narratiewe vlak lê, en is deel van die kuns van die Perse.

Die feit dat deel A soveel moeite doen om Xerxes deur ringkomposisie as $\beta \alpha \sigma i \lambda \varepsilon u ́ s$ te identifiseer, en dat hy in die middel van B net 'n $\alpha \nu \delta \rho \alpha$ genoem word, het

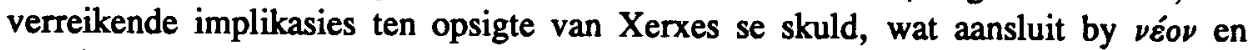

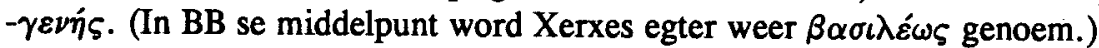

Clifton (1963:112) maak die stelling dat daar 'n kontras is tussen Xerxes as magtige koning voor die oorlog, en as ' $n$ "weak, human character" na die slag van Salamis. Dit lyk na 'n aantreklike kontras, maar ongelukkig sê Clifton niks verder hieroor nie. Die logiese stap is om te kyk na $\alpha \nu \alpha \nu \delta \rho i \alpha \varsigma$ in reël 755. By nadere ondersoek blyk dit dat $\alpha \dot{\alpha} \alpha \nu \delta \rho i \alpha \varsigma$ in die middelpunt van 'n ringkomposisie is, en onder andere omraam word deur 'slegte manne', na wie se verkeerde raad Xerxes geluister het. Die volle ringkomposisie word hier gegee:

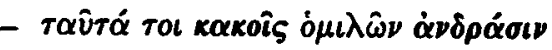

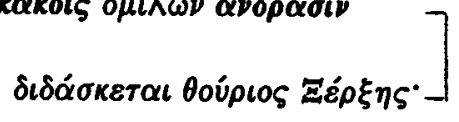

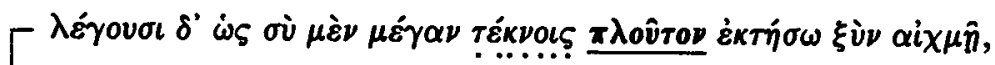

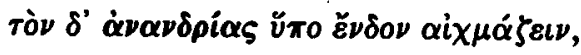

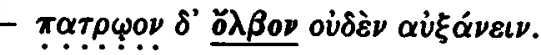

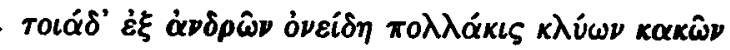

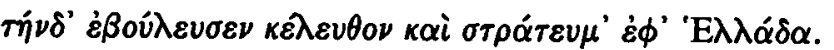

Die slegte raadgewers aan die buitekant word chiasties eers $\kappa \alpha \kappa o i \varsigma ~ \dot{\alpha} \nu \delta \rho \alpha ́ \sigma \iota$ en dan $\dot{\alpha} \nu \delta \rho \bar{\omega} \nu \kappa \alpha \kappa \hat{\omega} \nu$ genoem. In die middelpunt is die slap riem waarmee Xerxes gevang word, naamlik dat hy nie van $\dot{\alpha} \nu \alpha \nu \delta \rho i \alpha$ beskuldig wil word nie. In die tweede ring

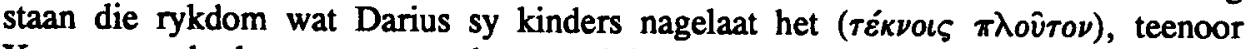
Xerxes se gebrek om sy voorvaders se rykdom ( $\pi \alpha \tau \rho \hat{\varphi} \circ \nu$ ŏ $\lambda \beta o \nu)$ te vermeerder.

Dit kan nie blote toeval wees dat $\check{\alpha} \nu \delta \rho \alpha$ in die middel van die ringkomposisie van deel B is, en $\dot{\alpha} \nu \alpha \nu \delta \rho i \alpha \varsigma$ ook in die middel van ' $n$ ringkomposisie is nie. Hier is eerder ' $n$ duidelike illustrasie van hoe Aiskhulos in die Perse stilistiese strukturering gebruik om verbande te lê op 'n meta-verbale vlak. Daar is nie 'n kontras tussen Xerxes as koning en ' $n$ val tot 'n gewone man nie, maar $\check{\alpha} \nu \delta \rho \alpha$ is deel van die 
uitbeelding van Xerxes se skuld as gevolg van verkeerde oordeel weens sy jeug. In die verlies tema word die soldate se dood veral uitgedruk in teenstellings soos

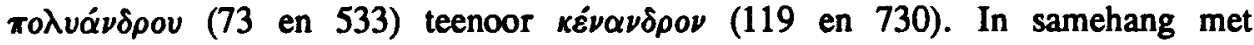
$\kappa \varepsilon ́ \nu \alpha \nu \delta \rho \circ \nu$ is $\dot{\alpha} \nu \alpha \nu \delta \rho \iota \alpha ́ \varsigma$ moontlik dubbelsinnig, om verlies van manne te suggereer.

Dele $A$ en $B$ word omraam deur 'n ring. Soos op die teksvoorstelling gesien kan word, het ' $E \lambda \lambda \alpha \alpha^{\prime}{ }^{\prime} \dot{\varepsilon} \varsigma \cdot \alpha \hat{L} \alpha \nu(\mathrm{A}(1))$ geen aansluiting in $\mathrm{A}$ nie. Dit sluit wel, boonop chiasties, aan by $\alpha$ $\sigma \tau v$ tò $\Pi \varepsilon \rho \sigma \hat{\omega} \nu$, by die end van deel B:

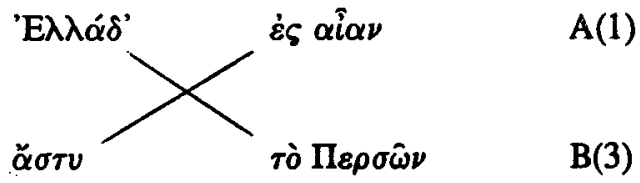

Hierdie verbinding is voorts deel van 'n meer uitgebreide omraming, deurdat $A(1)$ drie elemente het, net soos die parallelisme van $B$, wat elkeen aansluit by ' $n$ element $\operatorname{van} B(3)$ :

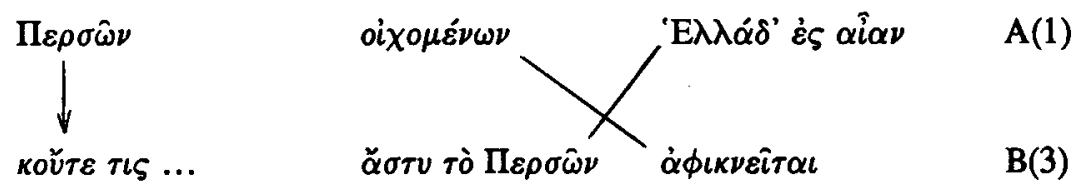

"Die Perse is weg na Griekeland ... niemand keer terug na Persië nie." Endersyds

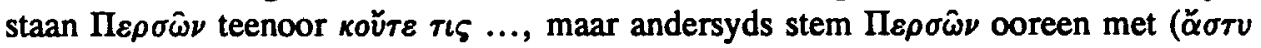

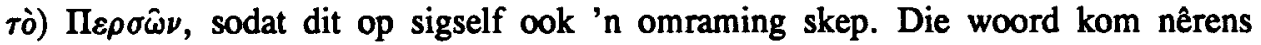
elders in die twee dele voor nie-dus word dit primêr vir omraming gebruik. Teenoor die weggaan aan die begin, keer niemand terug aan die einde nie.

Dit is duidelik dat baie motiewe en temas van die Perse deur die stilistiese strukturering gemerk word en dat selfs tematiese verhoudings geïmpliseer word, soos byvoorbeeld die kind-ouer konflik tussen Xerxes en die aarde van sy land; die kontras tussen Xerxes en die leër; en die vervanging van verlies aan rykdom deur verlies aan menselewens.

Terwyl deel $\mathrm{A}$ al hierdie elemente inlei en baie tentatief relasies suggereer, soos die onderskeid tussen die leër en die koning, is B, alhoewel baie korter as A, beide na struktuur en betekenis baie duideliker en dus 'n opsomming van A. Veral die kontras tussen die leër en Xerxes word baie duideliker gestel. Laastens gee die

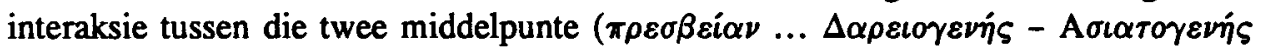
... $\nu \varepsilon^{\prime} \nu$ ) belangrike perspektief op die oorsaak van Xerxes se mislukking, naamlik sy jeug, sowel as op sy skuld, naamlik dat hy as kind van die land die ander kinders van die land se dood veroorsaak en daardeur verlies vir die ander betrokke partye veroorsaak.

Wat Perse 1-15 besonder maak, is dat die eerste deel se stylfigure en die implikasies daarvan ten opsigte van motiewe, deur die tweede deel herhaal word. Voorts laat vaar die tweede deel ook die onduidelikheid van die eerste deel en stel baie meer pertinent wat bedoel word. Hierdie herhaling vestig beide die aandag op die stylfigure en gee perspektief op die samehang van die motiewe, soos 
byvoorbeeld dat die verlies van goud minder belangrik is as die verlies aan menselewens. Hierdie tegniek van opsommende herhaling is, sover dit Aiskhulos betref, iets heel besonders, en kom na hierdie skrywer se wete net in die Perse voor.

'n Verdere unieke eienskap van die manier waarop motiewe hier aangedui word, is dat konraste tussen motiewe geld. So is daar kontraste tussen Xerxes se jeug en die koor se ouderdom, tussen die koningshuis en die leër, tussen goud en die manne se lewens, tussen weggaan en terugkom.

In die Perse word motiewe dus eerder deur strukturering as deur dubbelsinnigheid aandgedui. Voorts word dit alreeds in die openingsreëls gedoen, sodat die motiewe van die begin af herkenbaar is, anders as in die Oresteia, waar motięwe eers in retrospeksie duidelik word. In toekomstige artikels sal onder andere gewys word hoedat selfs die ontwikkeling van individuele motiewe, op sigself nuwe strukture skep.

Die motiewe wat deur die strukturering aangedui is, kan kortliks soos volg opgesom word: 'n Tema van grootskaalse lewensverlies word aangevoor deur 'n kontras tussen die baie Perse wat weg is en die feit dat geeneen nog teruggekeer het nie. Die koningshuis word teenoor die leër gestel en sodoende van die verlies-tema ontkoppel. Gevolglik is die moontlike verlies aan goud nie so belangrik soos die land se verlies aan sy kinders nie. Die oorsaak van die verlies is Xerxes se jeugdigheid, wat kontrasteer met die ouderdom en geïmpliseerde wysheid van die koor.*

\section{BIBLIOGRAFIE}

Clifton, G 1963. The mood of the Persai of Aeschylus. Greece and Rome 10, 111117.

Groeneboom, P 1960. Aeschylos' Perser. 2. Bd. Göttingen: Vandenhoeck \& Ruprecht.

Holtsmark, E B 1970. Ring composition and the Persae of Aeschylus. Symbolae Osloenses 45, 5-23.

Saayman, F 1994. The wrath of Artemis (and Menis!). Akroterion 39, 2-11.

Erkenning: Die TLG elektroniese teks is gebruik om woorde te soek. 